\title{
Diagnostic Utility of Creatine Kinase in Patients Presenting to the Emergency Department with Chest Pain
}

Brandon Lam ${ }^{1,2}$, Hina Chaudry², Muhammad Mukarram², Marie-Joe Nemnom², Soo-Min $\mathrm{Kim}^{2}$, Aline Christelle Ishimwe ${ }^{2}$, Monica Taljaard $^{2,3}$, Robert S. Beanlands ${ }^{4}$, Ronald Booth $^{5,6,}$ Guy Hebert ${ }^{7}$, Ian Stiell $2,3,7$, Venkatesh Thiruganasambandamoorthy ${ }^{2,3,7}$

${ }^{1}$ Faculty of Medicine, University of Ottawa, Ottawa Canada

2Ottawa Hospital Research Institute, Ottawa, Canada ${ }^{3}$ School of Epidemiology and Public Health, University of Ottawa, Ottawa, Canada ${ }^{4}$ Division of Cardiology, University of Ottawa, Ottawa, Canada

${ }^{5}$ Division of Biochemistry, The Ottawa Hospital, Ottawa, Canada

${ }^{6}$ Department of Pathology \& Lab Medicine, University of Ottawa, Ottawa, Canada ${ }^{7}$ Department of Emergency Medicine, University of Ottawa Ottawa, Canada

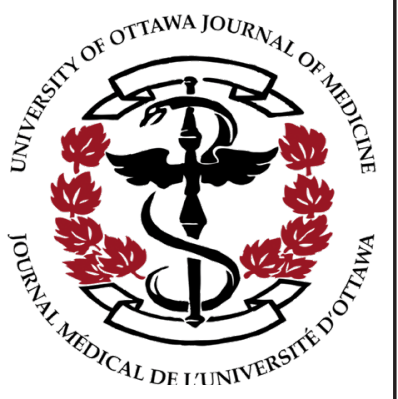

\section{ABSTRACT}

Introduction: Creatine Kinase (CK) is routinely performed in some emergency departments (ED) for Non-STelevation myocardial infarction (NSTEMI) workup. Its diagnostic utility is not well understood. The objectives of this study were to assess the value of CK in NSTEMI diagnosis in the troponin era and the association between the highest CK/Troponin values and ejection fraction (EF) during NSTEMI follow-up.

Methods: A prospective cohort study conducted at the two EDs of The Ottawa Hospital from March 2014 to March 2016 enrolled adults ( $\geq 18$ years) for whom troponin I (Tnl) and CK were ordered for NSTEMI symptoms. We excluded those with ST-Elevation Myocardial Infarction (STEMI). The primary outcome was a NSTEMI within 30 days. We used descriptive statistics and report test diagnostic characteristics with $95 \%$ confidence intervals $(\mathrm{Cl})$. We compared the highest median $\mathrm{CK} /$ Troponin values using Wilcoxon test.

Results: Of the 2,153 patients enrolled, 99 (4.6\%) suffered a NSTEMI. The sensitivity and specificity were: CK (cutoff $>250 \mathrm{U} / \mathrm{L}) 31.3 \%(95 \% \mathrm{Cl} 22.2,40.5)$ and $91.1 \%(95 \% \mathrm{Cl} 89.9,92.4)$ respectively; $\mathrm{Tnl}$ (cutoff $>0.045 \mu \mathrm{g} / \mathrm{L})$ $98.0 \%(95 \% \mathrm{Cl} 95.2,100)$ and $86.2 \%(95 \% \mathrm{Cl} 84.7,87.7)$ respectively. The median CK values were not significantly different between those with normal $(n=267)$ and abnormal EF $(n=55)$ on follow-up (107 U/L and $118 \mathrm{U} / \mathrm{L}$ respectively; $\mathrm{p}=0.31)$, whereas the median $\mathrm{Tnl}$ values were significantly different $(0.02 \mu \mathrm{g} / \mathrm{L}$ and 0.1 $\mu \mathrm{g} / \mathrm{L}$ respectively; $\mathrm{p}<0.0001)$.

Conclusions: CK measurements do not provide any value in the ED work-up of NSTEMI and is not associated with EF on follow-up. Discontinuing routine CK measurements would improve resource utilization.

\section{RÉSUMÉ}

Introduction: Le dosage de la créatine kinase (CK) est couramment effectué dans certains services d'urgence pour le bilan de l'infarctus du myocarde sans sus-décalage du segment ST (NSTEMI). Son utilité diagnostique n'est pas bien comprise. Les objectifs de cette étude étaient d'évaluer la valeur de la CK dans le diagnostic de l'infarctus du myocarde sans sus-décalage du segment ST à l'ère de la troponine et l'association entre les valeurs les plus élevées de CK/Troponine et la fraction d'éjection (FE) pendant le suivi de l'infarctus du myocarde sans sus-décalage du segment ST.

Méthodes: Une étude de cohorte prospective menée dans les deux urgences de l'Hôpital d'Ottawa de mars 2014 à mars 2016 a recruté des adultes ( $\geq 18$ ans) pour lesquels la troponine I (Tnl) et la CK ont été prescrites pour des symptômes de NSTEMI. Nous avons exclu les personnes présentant un infarctus du myocarde avec surélévation du segment ST (STEMI). Le résultat primaire était un NSTEMI dans les 30 jours. Nous avons utilisé des statistiques descriptives et rapporté les caractéristiques diagnostiques des tests avec des intervalles de confiance (IC) à 95\%. Nous avons comparé les valeurs médianes les plus élevées de CK/Troponine en utilisant le test de Wilcoxon.

Résultats: Sur les 2153 patients recrutés, 99 (4,6 \%) ont souffert d'un NSTEMI. La sensibilité et la spécificité étaient : CK (seuil >250U/L) 31,3\% (95\%Cl 22,2, 40,5) et 91,1\% (95\%Cl 89,9, 92,4) respectivement ; Tnl (seuil $>0,045 \mu \mathrm{g} / \mathrm{L}) 98,0 \%(95 \% \mathrm{Cl} 95,2,100)$ et $86,2 \%(95 \% \mathrm{Cl} 84,7,87,7)$ respectivement. Les valeurs médianes de CK n'étaient pas significativement différentes entre ceux qui avaient une FE normale $(n=267)$ et anormale ( $n=55$ ) lors du suivi (107 U/L et $118 \mathrm{U} / \mathrm{L}$ respectivement ; $p=0,31)$, alors que les valeurs médianes de Tnl étaient significativement différentes $(0,02 \mu \mathrm{g} / \mathrm{L}$ et $0,1 \mu \mathrm{g} / \mathrm{L}$ respectivement ; $\mathrm{p}<0,0001)$.

Conclusions: La mesure de la CK n'est d'aucune utilité dans l'évaluation de la NSTEMI aux urgences et n'est pas associée à la FE lors du suivi. L'abandon de la mesure systématique de la CK améliorerait l'utilisation des ressources.

Keywords: Chest Pain, Creatine Kinase, Non-ST Elevated Myocardial Infarction 


\section{INTRODUCTION}

Chest pain is the second most common emergency department (ED) presenting complaint with an estimated 600,000 patients presenting annually across Canada. 1 The etiology of chest pain varies from musculoskeletal to cardiac causes such as acute coronary syndrome (ACS). ACS encompasses unstable angina (UA), Non-ST Elevated Myocardial Infarction (NSTEMI), and ST- Elevated Myocardial Infarction (STEMI).2 STEMI is diagnosed by electrocardiogram (ECG) and UA is diagnosed clinically in absence of elevated cardiac biomarkers. NSTEMI is defined as a rise and/or fall in cardiac troponin (cTn) with at least one value above the 99th percentile upper reference limit with clinical symptoms of ischemia such as chest pain or shortness of breath.2 As STEMI and UA constitute only $30 \%$ of patients with ACS, it is patients with a suspected NSTEMI that take up a significant proportion of ED resources.3 Currently, cTn is considered the standard biomarker for NSTEMI diagnosis.4 However, CK (creatine kinase) is also released into the blood stream as myocardial cells become infarcted and is one of the first cardiac biomarkers available in history to assess for NSTEMI. 5 Hence, clinicians in several centers have been measuring serial CK levels in addition to cTn to rule-out NSTEMI. Additionally, in our center, patients hospitalized with NSTEMI have serial CK measurements performed and the peak CK levels documented on discharge.

The primary objective of this study was to assess the value of CK in NSTEMI diagnosis among ED patients with MI symptoms in the troponin era. The secondary objective was to evaluate the association between the highest CK or troponin I (Tnl) values and ejection fraction (EF) on followup after NSTEMI hospitalization.

\section{METHODS}

We conducted a prospective cohort study at two EDs of The Ottawa Hospital (Civic and General Campuses) from March 2014 to March 2016 with the primary objective of developing a pathway for optimal use of the conventional troponin assay. The secondary objective of this prospective study is to assess the role of CK in NSTEMI diagnosis. We enrolled adults (age $\geq 18$ ) for whom cTn and CK tests were ordered for NSTEMI symptoms within the past 24 hours. We excluded patients with STEMI. The study was approved by the Ottawa Health Science Network Research Ethics Board. Emergency physicians obtained consent and enrolled patients into the study. We collected patient demographics, medical history, cTn and CK values, disposition, final ED diagnosis, and EF on follow-up echocardiogram among patients hospitalized with an NSTEMI. The EF was reported as intervals, $>65 \%, 55 \%-65 \%, 45 \%-54 \%, 30 \%-44 \%$, and $<30 \%$. EF $\geq 45$ was considered normal while EF $<45$ was classified as abnormal. 6 Both ED academic centers use a conventional Siemens Vista Tnl assay.

The primary outcome was an NSTEMI within 30 days of the index ED visit. The outcomes were assessed by an adjudication committee comprised of two physicians who were blinded to the study data. A third physician adjudicated the outcome if there were any disagreements.

\section{Data analysis}

We described our patient population using mean with standard deviation (SD), or median with interquartile range (IQR) for continuous variables based on the distribution, and frequency with proportion for categorical variables respectively. We used 250U/L, the upper reference range limit for CK and $0.045 \mu \mathrm{g} / \mathrm{L}$, the 99th percentile for the normal population for $\mathrm{Tnl}$ as the cut-point thresholds. We report sensitivity and specificity for the two biomarkers for NSTEMI diagnosis. We report $95 \%$ confidence intervals (Cl) for the point estimates using either the large sample approximation or the exact binomial distribution where appropriate. We compared the median $\mathrm{CK}$ and $\mathrm{Tnl}$ values between patients in the EF categories (normal vs abnormal) using the Wilcoxon test. We used SAS (version 9.4) software for data analysis. As the primary objective was to develop a troponin pathway, the sample size was guided by this primary objective.

\section{RESULTS}

During the study period, of the 2,319 patients enrolled, 25 (1.1\%) patients did not have CK measured and we were unable to achieve 30-day follow-up among 141 (6.1\%) patients. The remaining 2,153 patients were included in the final analysis. Table 1 shows the baseline characteristics, medical history, ED management and outcomes among study patients. Ninety-nine or $4.6 \%(95 \% \mathrm{CI} 3.8 \%$ to $5.6 \%)$ of patients suffered a NSTEMI during the 30-day follow up period. Ninety patients were diagnosed with NSTEMI in the ED and nine patients after ED disposition. 
Table 1. Patient characteristics and outcomes.

\begin{tabular}{|l|l|}
\hline Variables & $\begin{array}{l}\text { No. (\%) of patients } \\
\text { N = 2,153 }\end{array}$ \\
\hline Age (yrs) & $62.9(15.7)$ \\
\hline Mean \pm SD & $1,175(54.6)$ \\
\hline Sex & \multicolumn{2}{l}{} \\
\hline Male & $667(31.0)$ \\
\hline Medical History & $180(8.4)$ \\
\hline Coronary artery disease & $1,026(47.7)$ \\
\hline Congestive heart failure & $391(18.2)$ \\
\hline Hypertension & $757(35.2)$ \\
\hline Diabetes & $170(7.9)$ \\
\hline Hyperlipidemia/Dyslipidemia & \\
\hline $\begin{array}{l}\text { Transient ischemic attack and } \\
\text { cerebrovascular accident }\end{array}$ & $548(25.5)$ \\
\hline $\begin{array}{l}\text { History of percutaneous coronary } \\
\text { interventions and coronary artery bypass gr } \\
\text { aft }\end{array}$ & \\
\hline Family history of coronary artery disease & $316(14.7)$ \\
\hline Previous cardiac arrest & $7(0.3)$ \\
\hline Current smoker & $237(11.0)$ \\
\hline ED Management \& 30-Day Outcomes & $99(4.6)$ \\
\hline NSTEMI within 30-days & $270(12.6)$ \\
\hline Hospitalized & \\
\hline
\end{tabular}

NSTEMI: Non-ST Elevation Myocardial Infarction

There were 213 patients (9.9\%) who had CK levels $>250 \mathrm{U} / \mathrm{L}$ and 31 of them were diagnosed with NSTEMI (Appendix 1). Conversely, 68 patients diagnosed with NSTEMI had a normal CK level. Table 2 shows the diagnostic characteristics of CK and Tnl. The sensitivity and specificity of CK for NSTEMI diagnosis was $31.3 \%(95 \% \mathrm{Cl} 22.2 \%$ to $40.5 \%)$ and $91.1 \%(95 \% \mathrm{Cl} 89.9 \%$ to $92.4 \%)$ respectively. Of the 99 patients with NSTEMI, Tnl was elevated Tnl among 97 patients. The sensitivity and specificity of $\mathrm{Tnl}$ was $97.9 \%(95 \% \mathrm{Cl} 95.2 \%$ to $100 \%)$ and $86.2 \%(95 \% \mathrm{Cl}$ $84.7 \%$ to $87.7 \%$ ). The paired agreement for CK and $\mathrm{Tnl}$ for NSTEMI diagnosis was $0.07(95 \% \mathrm{Cl} 0.03$ to 0.12$)$.

Table 2. Diagnostic characteristics of $\mathrm{CK}$ and Tnl

\begin{tabular}{|l|l|l|}
\hline $\begin{array}{l}\text { Diagnostic } \\
\text { Characteristics of } \\
\text { CK and Tnl }\end{array}$ & $\begin{array}{l}\text { Sensitivity } \mathbf{( 9 5 \%} \\
\text { Cl) }\end{array}$ & $\begin{array}{l}\text { Specificity } \mathbf{( 9 5 \%} \\
\text { Cl) }\end{array}$ \\
\hline CK & $31.3 \%(95 \% \mathrm{Cl}$ & $\begin{array}{l}91.1 \%(95 \% \mathrm{Cl} \\
89.9 \%-92.4 \%)\end{array}$ \\
\hline TnI & $22.2 \%-40.5 \%)$ & $86.2 \%(95 \% \mathrm{Cl}$ \\
& $97.9 \%(95 \% \mathrm{Cl}$ & $84.7 \%-87.7 \%)$ \\
\hline
\end{tabular}

CK: Creatine Kinase; Cl: Confidence Interval; Tnl: Troponin I
324 patients had an echocardiography performed within a mean of 22( \pm 25.6$)$ days after hospitalization. Table 3 shows the relationship between EF and highest median $\mathrm{CK} / \mathrm{Tn}$ l values. Patients with normal EF had a median CK value of $107 \mathrm{U} / \mathrm{L}$ (IQR 71 to 166) and those with abnormal EF had a median value of $118 \mathrm{U} / \mathrm{L}$ (IQR 72 to 195 ; $p=0.31$ ). For Tnl, patients with normal EF had a median $\mathrm{Tnl}$ value of $0.02 \mu \mathrm{g} / \mathrm{L}$ (IQR 0.02 to 0.13 ) and those with abnormal EF had a median value of $0.1 \mu \mathrm{g} / \mathrm{L}$ (IQR 0.03 to 0.65 ; $\mathrm{p}<0.0001)$.

Table 3. EF versus highest median $\mathrm{CK} / \mathrm{Tnl}$

\begin{tabular}{|l|l|l|}
\hline $\begin{array}{l}\text { Post-Admission } \\
\text { EF Versus High- } \\
\text { est Median CK/ } \\
\text { Tnl }\end{array}$ & $\begin{array}{l}\text { Highest Median } \\
\text { CK (IQR) (U/L) }\end{array}$ & $\begin{array}{l}\text { Highest Median } \\
\text { Tnl }(\text { IQR) }(\mu \mathrm{g} / \mathrm{L})\end{array}$ \\
\hline Normal EF $(\geq 45)$ & $107(71-166)$ & $0.02(0.02-0.13)$ \\
\hline Abnormal EF $(<45)$ & $118(72-195)$ & $0.1(0.03-0.65)$ \\
\hline
\end{tabular}

CK: Creatine Kinase; EF: Ejection Fraction; IQR: Interquartile Range; TnI: Troponin I

\section{Limitations}

We compared CK to a conventional Tnl assay. However, if compared to high-sensitive troponin assays such as Abbott ARCHITECT, Beckman ACCESS assays, the results may be more significant. Our study enrolled a random sample of patients and hence, selection bias is plausible.

\section{DISCUSSION}

While most centers have abandoned the routine CK measurements for evaluation of patients with NSTEMI symptoms, there are still a significant number of healthcare facilities that continue the practice of $\mathrm{CK}$ measurements in addition to CTn for chest pain.7,8 However, our study shows evidence that $\mathrm{CK}$ is not useful in NSTEMI diagnosis when another cardiac enzyme assay such as $\mathrm{Tnl}$ provides both a high sensitivity and specificity.

While the specificity of $\mathrm{CK}$ and $\mathrm{Tnl}$ were similar, $\mathrm{Tnl}$ has a markedly higher sensitivity. Due to Tnl's high sensitivity and specificity compared to CK, Tnl should be the only measurement used in patients with a suspected NSTEMI Among 2 patients that were diagnosed with NSTEMI with Tnl values below the cut-off, CK was also within normal limits and hence, had no diagnostic value.

Our study also shows that there is no statistically significant 
difference of the median $\mathrm{CK}$ value between normal and abnormal EF. Although EF may seem associated with CK, the CK median values do not go above the cutoff ( $>250 \mathrm{U} / \mathrm{L}$ ) meaning these values would not be considered to be abnormally elevated. Furthermore, as the Tnl values show an association for future low EF, there is no added benefit from CK measurements, and it is a waste of healthcare resources.

\section{CONCLUSION}

In conclusion, our study shows that $\mathrm{CK}$ adds no diagnostic value in the workup of a NSTEMI among patients with negative $\mathrm{Tnl}$ and hence should be discontinued. Our study shows no apparent association between highest median CK values and EF on follow-up echocardiogram. In contrast, Tnl shows better association with lower EF. Discontinuing CK measurements will decrease costs and improve resource utilization.

\section{REFERENCES}

1. Scheuermeyer FX, Wong H, Yu E, Boychuk B, Innes G, Grafstein E, Gin K, Christenson J. Development and validation of a prediction rule for early discharge of emergency department patients with potential ischemic chest pain. CJEM. 2014;16:106-19.

2. Kumar A, Cannon CP. Acute coronary syndromes: diagnosis and management, part I. Mayo Clin Proc. 2009;84(10):917938. doi:10.1016/S0025-6196(11)60509-0

3. Basit H, Malik A, Huecker MR. Non ST Segment Elevation (NSTEMI) Myocardial Infarction. StatPearls. 2019.

4. Thygesen K, Alpert J S, White H D. Universal definition of myocardial infarction. Circulation. 2017; 116, 2634-2653.

5. Al-Hadi HA, Fox KA. Cardiac Markers in the Early Diagnosis and Management of Patients with Acute Coronary Syndrome. Sultan Qaboos Univ Med J. 2009; 9(3):231-246.

6. Lang RM, Badano LP, Mor-Avi V, Afilalo J, Armstrong A, Ernande $\mathrm{L}$, et al. Recommendations for Cardiac Chamber Quantification by Echocardiography in Adults: An Update from the American Society of Echocardiography and the European Association of Cardiovascular Imaging. J Am Soc Echocardiogr. 2015;28(1):1-39.

7. Zhang L, Sill AM, Young I, Ahmed S, Morales M, Kuehl S. Financial impact of a targeted reduction in cardiac enzyme testing at a community hospital. J Community Hosp Intern Med Perspect. 2016; 6(5).

8. Wiens EJ, Arbour J, Thompson K, Seifer CM. Routine creatine kinase testing does not provide clinical utility in the emergency department for diagnosis of acute coronary syndromes. BMC Emerg Med. 2019; 19:37. 